\title{
Prediction of starch reserves in intact and ground grapevine cane wood tissues using
} near infrared reflectance spectroscopy (NIRS)

\author{
J.E. Jones ${ }^{1 *}$, A. Eyles ${ }^{1}$, C. Claye ${ }^{1}$, T. Rodemann' ${ }^{2}$ R.G. Dambergs ${ }^{3}$, D.C. Close ${ }^{1}$ \\ ${ }^{1}$ Tasmanian Institute of Agriculture, University of Tasmania, Private Bag 98, Hobart TAS \\ 7001, Australia. ${ }^{2}$ Central Science Laboratory, University of Tasmania, Hobart TAS 7001, \\ Australia. ${ }^{3}$ WineTQ, Monash, South Australia.
}

Running title: Development of a prediction tool for starch reserves in grapevine

Correspondence to: J Jones Tasmanian Institute of Agriculture, University of Tasmania, Private Bag 98, Hobart TAS 7001, Australia.Email: Joanna.Jones@utas.edu.au

This article has been accepted for publication and undergone full peer review but has not been through the copyediting, typesetting, pagination and proofreading process which may lead to differences between this version and the Version of Record. Please cite this article as doi: 10.1002/jsfa.10253 


\begin{abstract}
BACKGROUND: Near Infrared Reflectance Spectroscopy (NIRS) technology can be a powerful analytical technique for the assessment of plant starch, but generally samples need to be freeze-dried and ground. This study investigated the feasibility of using NIRS technology to quantify starch concentration in ground and intact grapevine cane wood samples (with or without the bark layer). A partial least squares (PLS) regression was used on the sample spectral data and was compared against starch analysis using a conventional wet chemistry method.
\end{abstract}

RESULTS: Accurate calibration models were obtained for the ground cane wood samples (n $=220$ ), one based on 17 factors $\left(\mathrm{R}^{2}=0.88\right.$, root mean square error of validation (RMSEV) of $\left.0.73 \mathrm{mg} \cdot \mathrm{g}^{-1}\right)$ and the other based on 10 factors $\left(\mathrm{R}^{2}=0.85\right.$, RMSEV of $\left.0.80 \mathrm{mg} \cdot \mathrm{g}^{-1}\right)$. In contrast, the prediction of starch within intact cane wood samples was very low $\left(\mathrm{R}^{2}=0.19\right)$. Removal of the cane bark tissues did not substantially improve the accuracy of the model $\left(\mathrm{R}^{2}\right.$ $=0.34)$. Despite these poor correlations and low ratio of prediction to deviation (RPD) values of 1.08-1.24, the root mean square error of cross-validation (RMSECV) values were 0.75$0.86 \mathrm{mg} \cdot \mathrm{g}^{-1}$ ) indicating good predictability of the model.

CONCLUSION: As indicated by low RMSECV values, NIRS technology has the potential to monitor grapevine starch reserved in intact cane wood samples. 
Keywords: carbohydrates, cane wood, Pinot Noir, Chardonnay,

\section{Introduction}

Deciduous woody species (such as Vitis vinifera) rely exclusively on starch reserves accumulated in summer to support new root and shoot growth in the following spring. ${ }^{1-4}$ Grapevine starch reserves stored in cane wood and root have been shown to vary within and between seasons depending on climatic and management factors ${ }^{5-6}$ and also between varieties. $^{2}$ Therefore, knowledge of starch level in winter would provide opportunities to make informed management decisions for the subsequent season.

Traditionally, quantification of starch concentration has relied on wet chemistry analytical methods based on colourimetric or chromatography analyses. ${ }^{4,7-8}$ These methods are time consuming and labour intensive with samples typically dried and ground before extraction with a solvent in the laboratory. Recent work has highlighted the lack of consistency in starch measurement among wet chemistry methods and laboratories. ${ }^{9-10}$ Alternative approaches have been explored including reflectance spectroscopy combined with on-solid iodine complexation $^{11}$ and in vivo $\mathrm{x}$-ray micro CT technology ${ }^{12}$. Chemometrics combined with nearinfrared reflectance spectroscopy (NIRS) has the potential to provide a faster and more reliable approach for quantification of starch concentration in various tissues. ${ }^{13-14}$ 
NIRS is a powerful technique that has enabled rapid analysis of various compositional parameters in wine grapes, must and grapevine tissues ${ }^{13,15-16}$, grapevine water potential ${ }^{17-19}$ and starch. Accurate predictive models of starch have been reported for a range of woody tree systems including grapevine, Vitis spp. ${ }^{8,20-21}, 73$ tree species ${ }^{22}$ and Eucalyptus globulus ${ }^{23}$ using dried and ground samples. It is currently unknown if NIS can be used to predict starch on intact cane wood samples though this technology has been used to successfully predict a range of chemical and physical wood properties of intact timber samples. The accuracy of the models was influenced by factors such as sample surface preparation, sample thickness and surface texture. ${ }^{24-26}$

In contrast to conventional wet chemistry methods, NIRS could allow analysis of a large number of samples as sample preparation is relatively straightforward and no chemical reagents are necessary. Further, the possibility of simplifying sample presentation i.e. using whole canes instead of ground samples could dramatically increase sample throughput and potentially allow for non-destructive in vivo measurement in the field with a portable NIRS.

In experiments described here, starch concentration of ground and intact grapevine cane wood tissues was analysed using a traditional wet chemistry method as well as by spectral analysis to explore the potential for using multivariate data analysis to develop a rapid tool for the estimation of starch concentration in intact and ground grapevine tissues. To our knowledge, this is the first study to report the feasibility of NIR spectroscopy for the 
determination of starch in intact cane wood samples, with or without bark. We hypothesised that removing bark, which could interfere with the NIR starch signal, may improve the accuracy of the predictive model.

\section{Materials and methods}

\section{Plant material}

In 2010 ( $n=59), 2011(n=107)$ and $2012(n=39)$, cane wood samples were sourced from five commercial vineyards in southern Tasmania, Australia (vineyard a: $42^{\circ} 37^{\prime} 55^{\prime}$ S, $146^{\circ} 48$ ’2”’E; vineyard b: 4248’28’S, $147^{\circ} 25^{\prime} 42^{\prime}$ E; vineyard c: $42^{\circ} 45^{\prime} 49^{\prime}$,

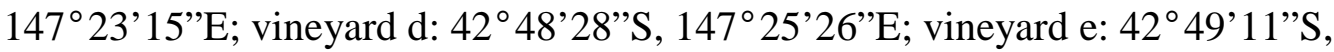
$\left.147^{\circ} 50^{\prime} 32^{\prime} \mathrm{E}\right)$. These samples were chosen to represent a range of analytical values, growing years, conditions (aspect, soil, vine age (i.e. 8 to 16 years-old) and vigour), pruning systems (cane and spur pruning) and grape varieties (i.e. Pinot Noir and Chardonnay growing on own roots). The climate is cool temperate with an annual mean rainfall of $\sim 600 \mathrm{~mm}$ (Australian Bureau of Meteorology, www.bom.gov.au). The rainfall in 2010, 2011, 2012 and 2018 was 531, 759, 595.5 and $535.2 \mathrm{~mm}$, respectively (www.bom.gov.au). It is worthy to note that the total annual rainfall in 2011 was 27\% higher than the long-term average value. Mean daily maximum/minimum temperatures are $22.5 / 12.5^{\circ} \mathrm{C}$ and $12.0 / 4.0^{\circ} \mathrm{C}$ in summer and winter, respectively (www.bom.gov.au). To minimize tissue variability due to unstable phenological phases, all wood samples were collected during winter dormancy at pruning (June). 
Additional samples harvested in $2018(\mathrm{n}=148)$ were sourced from vineyard c, Pinot Noir block. The vines were 18-years-old and cane pruned.

\section{Sample preparation for grinding}

Cane internodes (excluding buds) collected in 2010-2012 were cut into approximately $3 \mathrm{~cm}$ segments, and freeze-dried using a freeze-drier (Christ beta 1-8LD plus). These samples were firstly ground to be able to pass through a $1 \mathrm{~mm}$ sieve using an IKA Cutting Mill (A11 basic Analytical mill) then all samples were finely ground into a powder using a Mixer Mill MM 200 (Retsch, Haan, Germany). Samples from 2018 were freeze-dried as above, then directly ground into a fine powder with a Mixer Mill MM 200. All ground samples were stored at -20

${ }^{\circ} \mathrm{C}$ pending NIR analysis, which was carried out within one month following collection in each season. Every tenth sample was done in triplicate to assure quality control of the laboratory method. The laboratory error of $0.19 \mathrm{mg} \cdot \mathrm{g}^{-1}$ was determined by the average standard deviation of the triplicate analysis.

\section{Spectral measurements}

NIRS analysis was performed using a FT-NIR spectrophotometer (Bruker MPA, Ettlingen, Germany) at ambient temperature $\left(\sim 20^{\circ} \mathrm{C}\right)$. Ground samples were placed into $7 \mathrm{~mL}$ glass vials for NIRS analysis. For the fresh intact cane wood samples, NIR spectra of each sample were recorded using a fibre optic probe at five different positions along the cane segment, which were then averaged to a single spectrum. Immediately after, this procedure was 
repeated on the same sample after the bark had been removed using a scalpel. Absorbance spectra were taken from 12,500 to $4000 \mathrm{~cm}^{-1}$ with a spectral resolution of $8 \mathrm{~cm}^{-1}$ and 64 scans (vials) or 5 x 4 scans (fibre optic probe) per sample. The intact samples were then progressed to freeze drying and grinding as explained previously.

\section{Chemical analysis}

Soluble sugars were extracted from $100 \mathrm{mg}$ powdered samples in $3 \mathrm{~mL}$ of $80 \%$ ethanol incubated in a water bath $\left(60^{\circ} \mathrm{C}\right)$ for 1 hour and then centrifuged $(4000 \mathrm{~g})$ for $10 \mathrm{~min}$ at 16 ${ }^{\circ} \mathrm{C}$. The extraction was repeated twice. The concentration of insoluble starch (expressed in $\mathrm{mg} \mathrm{g}^{-1}$ of glucose equivalents) was analysed using a commercial enzyme assay kit (Total Starch Assay Procedure, K-TSTA-50A/K-TSTA-100A 08/16, Megazyme International, Bray, Ireland). The samples were determined with a Genesys 10S UV-Vis spectrometer (Thermo Fisher Scientific, Madison, WI, USA). Standardized regular maize starch control was used for the calibration curve. A D-(+)-glucose standard $(1.0 \mathrm{mg} / \mathrm{mL}$ in $0.2 \%(\mathrm{w} / \mathrm{v})$ benzoic acid) was run with every batch of 10 samples. The starch concentrations are reported as the percentage of dry matter.

\section{Chemometrics and data analysis}

A partial least square (PLS) regression model was created correlating the quantitative starch data with the corresponding NIR spectra using the Unscambler ${ }^{\circledR}$ X software (version 10.1, CAMO Software, Oslo, Norway). Principal component analysis was performed to detect 
potential spectral outliers ${ }^{27}$, defined as those data points having a Mahalanobis distance (i.e. data point to centroid) greater than three. ${ }^{28}$

We used the NIPALS algorithm (Non-linear Iterative PLS) for the determination of loadings and scores. The scores and loadings were calculated pair-by-pair by an iterative procedure. For the ground cane wood starch model, the data set was randomly divided into two groups prior to applying the PLS procedure - one group would be used for either the calibration model $(n=220)$ or the external validation model $(n=133)$ to assess the calibration equation as a prediction model. We chose the external validation approach over the cross-validation procedure to obtain true independent validation ${ }^{29}$. For the intact cane wood samples, crossvalidation of the model was preferred due to overall small sample number.

Numerous calibration models were trialled using different and a combination of spectral pre-processing and spectral ranges. The performance of the validation and cross-validation models were evaluated by the root mean square error of validation (RMSEV) or the root mean square error of cross-validation (RMSECV), the bias, ratio of performance deviation (RPD), the regression coefficient $\left(\mathrm{R}^{2}\right)$ between the predicted and reference values and RMSEV relative to the laboratory error. RMSEV or RMSECV expresses the average error of validation that is indicative of the error for future predictions when the model is applied to unknown samples. ${ }^{30}$ RPD (calculated from the ratio of the SD of laboratory references values to RMSEV or RMSECV) is a useful statistic that gives an assessment of the predictive power of the model relative to the data range. The RPD values should be larger than 2.5, however, lower RPD values can result from a narrow range of the reference values (small 
SD) or to a large error in the prediction (RMSEV or RMSECV) as compared with the variability of the reference values ${ }^{31-32}$.

\section{Results}

\section{Ground cane wood samples}

Table 1 shows the range between maximum and minimum values, mean and SD for starch concentration of the calibration and the validation sets analysed by reference methods. Chemical variation found in the reference analyses could be considered acceptable and wide enough for the development of the aimed calibration equations for the ground cane wood samples however, it the range of the intact cane wood samples was more limited (i.e. 5.9 to 8.3\%) (Table 1). Figure 1 shows the absorbance spectra of all ground cane wood samples. The wave number range of $4250-8000 \mathrm{~cm}^{-1}$ was used to develop the calibration models.

The score plots of Factors 1 and 3 of the starch prediction model indicate that clustering of spectral data was evident for growing season (Fig. 2) but not variety, pruning method and vineyard (data not presented). Despite this clustering, PLS regression of NIRS spectra and laboratory values produced a good calibration model (Fig. 3; Table 2). The best calibration model based on high $\mathrm{R}^{2}$ and low RMSEV was achieved by using a Multiplicative Scatter Correction (MSC) for the spectral range between 4246-9404 $\mathrm{cm}^{-1}$. A 17-factor model gave the highest $\mathrm{R}^{2}$ and the lowest RMSEV (Model A; $\mathrm{R}^{2}=0.88$, RMSE $=0.73 \mathrm{mg} \cdot \mathrm{g}^{-1}$ ), however, a much simpler model comprising of only 10 factors (Model B) produced an only marginal lower $\mathrm{R}^{2}$ of 0.85 and a slightly higher RMSEV of $0.80 \mathrm{mg} \cdot \mathrm{g}^{-1}$ (Table 2). The RPD values of 
both models were above 2.5 (Table 2). The histogram plot of starch concentrations of ground cane wood samples (Appendix 1a) showed a non-normal distribution due to the skew towards high measured starch results.

Factors 1 to 3 explained 64\% of the variation (i.e. Factor 1: 49\% (variance), 13\% (contribution to the model), Factor 2: 47\%, 10\%, Factor 3: 3\%, 41\%). Factors 1 to 3 and in particular, Factor 3, show that the major regions of interest occurred between 4000 to 8000 $\mathrm{cm}^{-1}$ (Fig. 4), a region that contains many vibrational signals related to starch. ${ }^{33}$ In particular, dominant bands attributed to starch included 5300-5200 $\mathrm{cm}^{-1}$ (amylose and amylopectin helix structures), 4700-4600 $\mathrm{cm}^{-1}$ (C-H stretching and C-O stretching combination) and 4420-4283 $\mathrm{cm}^{-1}$ (C-H stretching and $\mathrm{CH}_{2}$ deformation combination band). In addition, the complexity of the model suggests that it most likely also includes variation in lignin and cellulose.

\section{Intact cane wood samples}

NIR spectra of intact wood sample correlated poorly with the starch values as indicated by the low $\mathrm{R}^{2}$ (0.19) and RPD (1.08) values (Table 1). The removal of bark did not improve the accuracy of the predictive model (0.34; Table 1$)$. However, the low RMSEV values $(<0.85$ mg. $\mathrm{g}^{-1}$ ) of intact cane wood indicate similar predictability of the model, and was comparable to the larger data set of ground cane wood samples. The histogram plot of starch concentrations for intact cane wood show a non-normal distribution with a skew towards medium values due to a lack of low starch concentrations < 6\% (Appendix 1). 


\section{Discussion}

A good predictive model was obtained for freeze dried and ground cane wood, as similarly reported for ground grapevine trunk tissues using PLS and NIRS $\left(\mathrm{R}^{2}=0.79\right.$ and RMSEP= $\left.1.29 \% \mathrm{DW}^{21}\right)$, and PLS and ATR-FT-MIR $\left(\mathrm{R}^{2}=0.95\right.$ and RMSEP $\left.=1.43 \% \mathrm{DW}^{20}\right)$. While the predictability of Model B was better than Model A, Model A is more robust in practical applications as it is based on 10 factors only. Histogram plots of starch concentrations show a non-normal distribution due to the skew towards the high measured starch results. Therefore, the accuracy of model A could be further improved by expanding the dataset to include additional low starch values. Despite the first three factors explaining 99\% of the spectral variation, a further seven were required to improve the accuracy of the model - such a high number most likely reflects the complexity of the data set, which included samples obtained across four growing seasons, two grape varieties, two pruning systems and five commercial vineyards. Although only growing season was found to cause clustering of the spectral data (most likely due to differences in total annual rainfall, particularly in 2011), the other factors are also likely to contribute to the variation of the data set. Nonetheless, the RPD values of both models were above 2.5, indicating that both models are very reliable. The relative error of RMSEV versus laboratory error of the triplicate starch measurements was surprisingly high ranging from 3.8 to 4.2, however this is partly due to a very low laboratory error (i.e. $0.19 \mathrm{mg}^{-1} \mathrm{~g}^{-1}$ ) as determined in this study as compared to previous studies which are much higher, ranging from e.g. 3-5 mg.g ${ }^{-1}{ }^{23}$ 
The correlation of NIR spectra to starch concentration for intact cane wood samples was poor, even with the removal of the bark layer. A closer examination of the distribution of starch granules in cane wood confirm that they are largely occurring in the ray parenchyma of the xylem and phloem (Fig. 5). For such non-homogenous samples, capturing this large variation may be challenging, particularly as the penetration depth into the sample of reflectance measurements is quite small. According to the literature, the penetration depth of wood tissue and powders can range from $300 \mu \mathrm{m}$ up to $4 \mathrm{~mm}$ depending on the physical, optical and composition characteristics of the sample. ${ }^{34-35}$

NIRS analysis of intact Pinus taeda wood samples showed poor calibrations of specific gravity and insoluble lignin, most likely due to variation in moisture content and surface roughness. ${ }^{36}$ In contrast, good calibrations $\left(\mathrm{R}^{2}: 0.75\right.$ - 0.84, SEC:1.02-1.37) were developed for predicting extractives, lignin and cellulose contents from solid wood samples of $E$. globulus. ${ }^{24}$ Strong calibrations of physical properties (e.g. density, modulus of elasticity and modulus of rupture) were obtained for intact wood surfaces (both radial and transverse), particularly using a larger-sized probe (spot size of $10 \mathrm{~mm}$ ) which enabled it to capture more sample variability. ${ }^{26}$ In this study, the probe circular spot size was $3 \mathrm{~mm}$, and we addressed the heterogeneity of the cane wood surface by analysing 5 different spots. However, this could not address the variation in the longitudinal distribution of starch in the sample.

Despite the poor correlation and low RPD, it is worthy to note that the RMSECV values of intact cane wood samples were similar to those obtained for ground cane wood samples 
suggesting good predictability of the model. As shown is Appendix 1, there was a nonnormal distribution with a skew towards medium values in the intact cane wood samples. Previous work has demonstrated RPD to be a less reliable indicator of the quality of the model for non-normally distributed datasets. ${ }^{37}$ As such, future work should aim to include a more even distribution of a large range of starch concentrations to improve the correlation. Further, increased sampling that includes season and variety variability would also allow the development of a more robust model, as has already been developed for ground plant samples. ${ }^{9,14,21}$ Therefore, it is still worth pursuing the use of intact samples for predicting starch concentration by NIRS, if not for non-destructive real time measurements in the field, but to reduce the sample preparation time of collected samples. Collecting NIR spectra from transverse and/or longitudinal sections of the cane wood rather than from the outer surface of the cane wood, as done in this study, may also help improve the correlation. Similar to the standard procedure used for intact timber core increments, these intact cane wood samples could also be dried to reduce the effect of moisture content on the accuracy of the model. While the values associated with ground wood calibrations have shown to be generally higher than those obtained for solid wood ${ }^{24,}$ the advantages to using solid wood calibrations may outweigh the slight decrease in accuracy.

\section{Conclusions}

Consistent with previous studies, the current results show that NIRS technique is suitable for the determination of grapevine reserve carbohydrate of ground cane wood samples, despite clustering across growing year. For the intact cane wood samples, while only a single season 
was examined, the results indicated that, despite poor calibrations, NIRS has the potential to assess the starch content of intact cane stems as evidenced by low RMSECV values. Contrary to our hypothesis, removal of the cane bark tissues did not substantially improve the accuracy of the model.

\section{Acknowledgements}

This research was supported by an industry consortium through an AusIndustry, Industry Cooperative Innovation Program. We thank Dr Noel Davies from the Central Science Laboratory for HPLC analysis of samples. We are grateful to Meadowbank, Frogmore Creek, Tolpuddle, Breamcreek, and 572 Richmond Rd vineyards for samples. We thank Widad Al Shawi and David Hayward from the Tasmanian Institute of Agriculture for technical assistance. We thank three anonymous reviewers for valuable comments on an earlier draft of the manuscript.

\section{References}

1. Candolfi-Vasconcelos,MC, Koblet W, Howell GS and Zweifel W, Retranslocation of carbon reserves from the woody storage tissues into the fruit as a response to defoliation stress during the ripening period in Vitis vinifera. Am J Enol Vitic 45:173 (1994).

2. Zapata C, Deléens E, Chaillouc S and Magné C, Partitioning and mobilization of starch and N reserves in grapevine (Vitis vinifera L.). J Plant Physiol 161:1031-1040 (2004). 
3. Bennett J, Jarvis P, Creasy G and Trought. MCT, Influence of defoliation on overwintering carbohydrate reserves, return bloom, and yield of mature Chardonnay grapevines. Am J Enol Vitic 56:386-393 (2005).

4. Holzapfel BP and Smith JP, Developmental stage and climatic factors impact more on carbohydrate reserve dynamics of shiraz than cultural practice. Am J Enol Vitic 63:3 (2012).

5. Heazlewood JE, Wilson S, Clark RJ and Gracie AJ, Pruning effects on Pinot noir vines in Tasmania (Australia). Vitis 45:165-171 (2006).

6. Pellegrino A, Clingeleffer P, Cooley N, Walker R, Management practices impactvine carbohydrate statust a greater extent than vineproductivity. Front Plant Sci 5:article 283 (2014).

7. Eyles A, Pinkard EA, Davies N, Corkrey R, Churchill K, O'Grady AP, Sands PJ, Mohammed C, Whole plant- and leaf- level regulation of photosynthetic responses after partial defoliation in Eucalyptus globulus saplings. J Exp Bot 64:1625-1636 (2013).

8. Jones JE, Claye C, Rodemann T, Dambergs RG and Close DC, Predicting grapevine starch levels using infrared spectroscopy in Proceedings of the 18th Symposium GiESCO. Ed by S. Amancio. University of Porto, Portugal, p. 471 (2013).

9. Quentin AG et al. Non-structural carbohydrates in woody plants compared among laboratories. Tree Physiol 35:1146-65 (2015).

10. Landhäusser SM, Standardized protocols and procedures can precisely and accurately quantify non-structural carbohydrates. Tree Physiol 38:1764-1778 (2018). 
11. Rustioni L, Ciacciulii A, Zulini L, Zuliani E, Sivilotti P and Herrera JC, Starch quantification in woody tissues by reflectance spectroscopy and onsolid iodine complexation. Sci Hortic 226 117-121 (2017).

12. Earles JM, Knipfer T, Tixier A, Orozco J, Reyes C, Zwieniecki MA, Brodersen CR and McElrone AJ, In vivo quantification of plant starch reserves at micrometer resolution using X-ray microCT imaging and machine learning. New Phytol 218:1260-1269 (2018).

13. Cozzolino D, Dambergs RG, Cynkar WU, Janik L and Gishen M, Analysis of grapes and wine by near infrared Spectroscopy. J Near Infrared Spec 14:279-289. (2006).

14. Pomares-Ticiana T, Martínez-Valdivieso D, Font R, Gómez P and del Río-Celestino M, Characterisation and prediction of carbohydrate content in zucchini fruit using near infrared spectroscopy. J Sci Food Agric 98:1703-1711 (2018)

15. Dambergs R, Gishen M and Cozzolino D, A review of the state of the art, limitations, and perspectives of infrared spectroscopy for the analysis of wine grapes, must, and grapevine tissue. Appl Spectros Rev 50:261-278 (2015).

16. Urraca R, Sanz-Garcia A, Tardaguilac J and Diago MP, Estimation of total soluble solids in grape berries using a hand-held NIR spectrometer under field conditions. J Sci Food Agric 96:3007-3016 (2016).

17. De Bei R, Cozzolino D, Sullivan W, Cynkar W, Fuentes S, Dambergs R, Pech and Tyerman S, Non-destructive measurement of grapevine water potential using near infrared spectroscopy. Aust J Grape Wine Res 17:62-71 (2011). 
18. Giovenzana V, Beghi R, Parisi S, Brancadoro L and Guidetti R, Potential effectiveness of visible and nearinfrared spectroscopy coupled with wavelength selection for real time grapevine leaf water status measurement. J Sci Food Agric 98:1935-1943 (2018).

19. Diago MP, Fernández-Novales J, Gutiérrez S, Marañón M and Tardaguila J, Development and validation of a new methodology to assess the vineyard water status by onthe-go near infrared spectroscopy. Front Plant Sci 9:article 59 (2018).

20. Schmidtke LM, Rapid monitoring of grapevine reserves using ATR-FTIR and chemometrics. Anal Chim Acta 732:16-25 (2012).

21. Bei De R, Fuentes S, Sullivan W, Edwards EJ, Tyerman EJ and Cozzolino D, Rapid measurement of total non-structural carbohydrate concentration in grapevine trunk and leaf tissues using near infrared spectroscopy. Comp Elect Agric 136:176-183 (2017).

22. Ramirez JA, Posada JM, Handa T, Hoch G, Vohland M, Messier C and Reu B, Nearinfrared spectroscopy (NIRS) predicts nonstructural carbohydrate concentrations in different tissue types of a broad range of tree species. Methods Ecol Evol 6:1018-1025 (2015).

23. Quentin AG, Rodemann T, Doutrelau MF, Moreau M and Davies NW, Application of near-infrared spectroscopy for estimation of non-structural carbohydrates in foliar samples of Eucalyptus globulus Labilladière. Tree Physiol 37:131-141 (2017).

24. Poke FS and Raymond CA, Predicting extractives, lignin, and cellulose contents using near infrared spectroscopy on solid wood in Eucalyptus globulus. $J$ Wood Chem Tech 26:187199 (2006). 
25. Thumm A, Riddell M, Nanayakkara B, Harrington J and Meder R, Mapping within-stem variation of chemical composition by near infrared hyperspectral imaging. J Near Infrared Spectrosc 24:605-616 (2016).

26. Schimleck LR, Matos JLM, Trianoski R and Prata JG, Comparison of methods for estimating mechanical properties of wood by NIR spectroscopy. J Spectrsc Article ID 4823285 (2018).

27. Shetty N, Gislum R, Jensen AMD and Boelt B, Development of NIR calibration models to assess year-to-year variation in total non-structural carbohydrates in grasses using PLSR. Chemometr Intell Lab Sys 111:34-38 (2012)

28. Shenk J, Workman J, Westerhaus M and Abrams S, Protocol for NIR calibration: monitoring analysis results and recalibration. In: Martens G, Shenk J, Barton F (eds) Near infrared spectroscopy (NIRS): Analysis of forage quality. Agriculture Handbook, USDAARS, US Government Printing Office, Washington, DC, pp 104-110 (1989).

29. Niemöller A and Behmer D, Use of near infrared spectroscopy in the food industry. In: Irudayaraj J, Reh C (eds) Nondesructive testing of food quality. Blackwell publishing, Oxford, UK, pp 67-118 (2008).

30. Font R, del Río-Celestino M and de Haro-Bailón A, The use of near-infrared spectroscopy (NIRS) in the study of seed quality components in plant breeding programs. Ind Crop Prod 24:307-313 (2006).

31. Fearn, T. Assessing calibrations: SEP, RPD, RER and R2. NIR News 13:12-14 (2002). 
32. Saeys W, Mouazen AM, Ramon H, Potential for onsite and online analysis of pig manure using visible and near infrared reflectance spectroscopy. Biosyst Eng 91:393-402 (2005).

33. Osborn BG, Fearn T and Hindle PH, Practical NIR Spectroscopy with Applications in Food and Beverage Analysis, 2nd edition. Longman Scientific and Technical, Singapore. (1993).

34. Yeh TF, Chang HM and Kadla JF, Rapid prediction of solid wood lignin content using transmittance near-infrared spectroscopy. J Agric Food Chem 52:1435-1439 (2004).

35. Schwanninger M, Rodrigues JC and Fackler K, A review of band assignments in near infrared spectra of wood and wood components. J Near Infrared Spectrosc 19:287-308 (2011).

36. Jones PD, Schimleck, LR, Daniels RF, Clark A and Purnell RC, Comparison of Pinus taeda L. whole-tree wood property calibrations using diffuse reflectance near infrared spectra obtained using a variety of sampling options. Wood Sci Tech 42:385-400 (2008).

37. Bellon-Maurel V, Fernandez-Ahumada E, Palagos B, Roge, JM. and McBratney A, Critical review of chemometric indicators commonly used for assessing the quality of the prediction of soil attributes by NIR spectroscopy. TrAC Trend Anal Chem 29:1073-1081 (2010). 
Table 1. Statistical summary for the parameters used in the present paper, separately showing the a) calibration and b) validation datasets. $\mathrm{SD}=$ standard deviation. Standard error of laboratory $=0.19 \mathrm{mg} \cdot \mathrm{g}^{-1}$

\section{Sample (n) Mean Min Max SD}

Calibration data set

Starch concentration (mg.g ${ }^{-1}$ ) of ground 220

$\begin{array}{llll}6.7 & 1.8 & 10.4 & 1.87\end{array}$

cane wood samples (2010-2012 \& 2018)

Validatation data set

Starch concentration (mg.g $\left.\mathrm{g}^{-1}\right)$ of ground 133

$\begin{array}{llll}6.9 & 2.1 & 10.4 & 2.08\end{array}$

cane wood samples (2010-2012 \& 2018)

Starch concentration (mg.g $\left.{ }^{-1}\right)$ of intact

147

$\begin{array}{llll}8.2 & 5.9 & 10.8 & 0.93\end{array}$

cane wood samples (2018 only) 
Table 2. Calibration statistics for the estimation of starch concentration (mg. $\mathrm{g}^{-1}$ ) for ground and intact cane wood (Vitis vinifera) obtained by PLS regression.

\begin{tabular}{lccc}
\hline Sample type & Bias & $\mathrm{R}^{2}(\mathrm{~V})$ or R$^{2}(\mathrm{C})$ & RMSEV or RESEC (mg.g $\left.{ }^{-1}\right)$ RPD \\
\hline Ground cane wood samples* & & & 0.80 \\
Independent validation Model A (10 factors) & -0.01 & 0.85 & 0.73 \\
& & & 2.6 \\
Independent validation Model B (17 factors) & -0.05 & 0.88 & 2.85 \\
2018 intact cane wood (with bark) & & & 0.86 \\
Cross-validation data & 0.004 & 0.20 &
\end{tabular}

\section{8 intact cane wood (no bark)}


* included data from 2010, 2011, 2012 and 2018 growing seasons, RPD (residual predictive deviation) = SD of laboratory values/RMSEV or RMSEC 


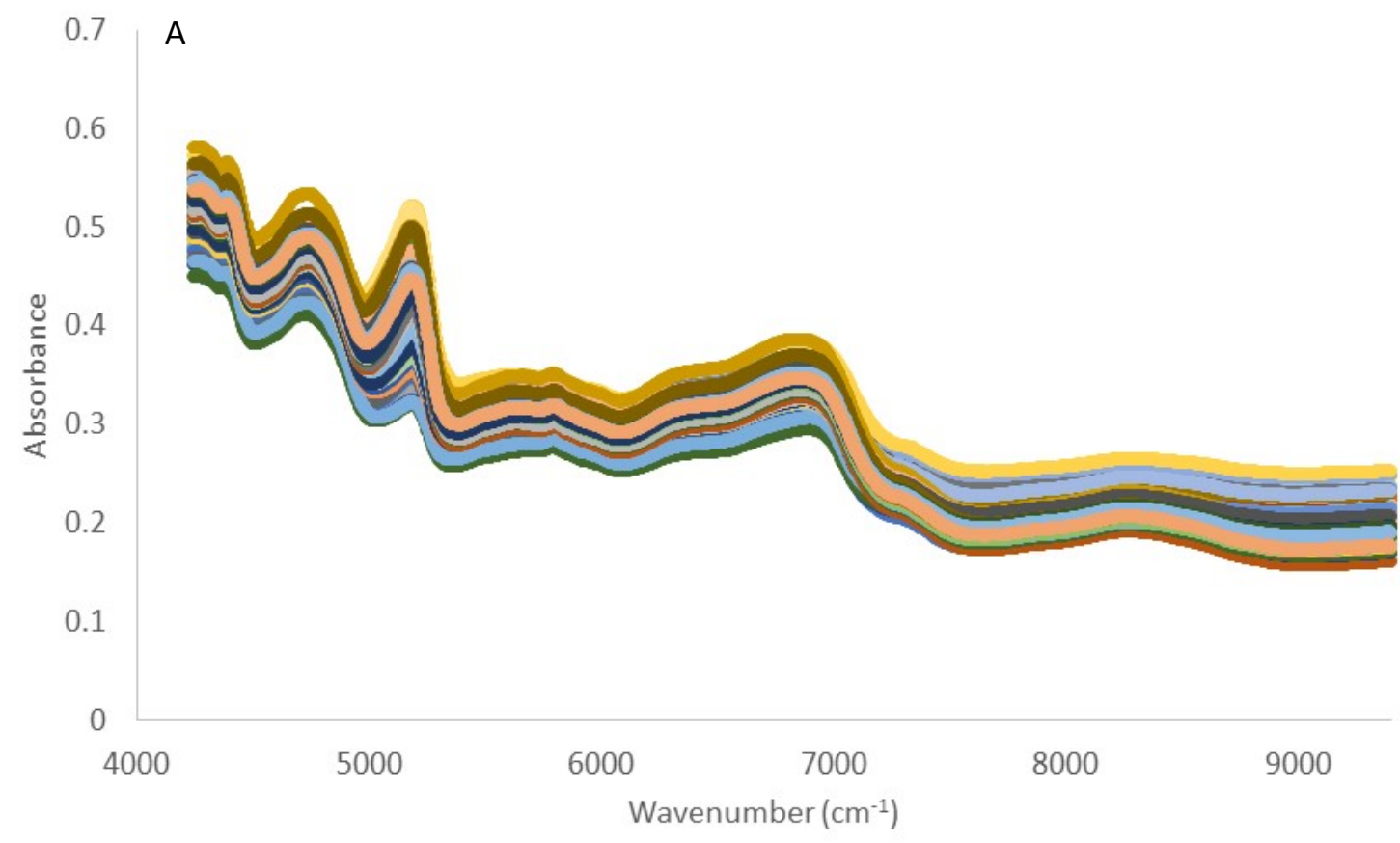

B

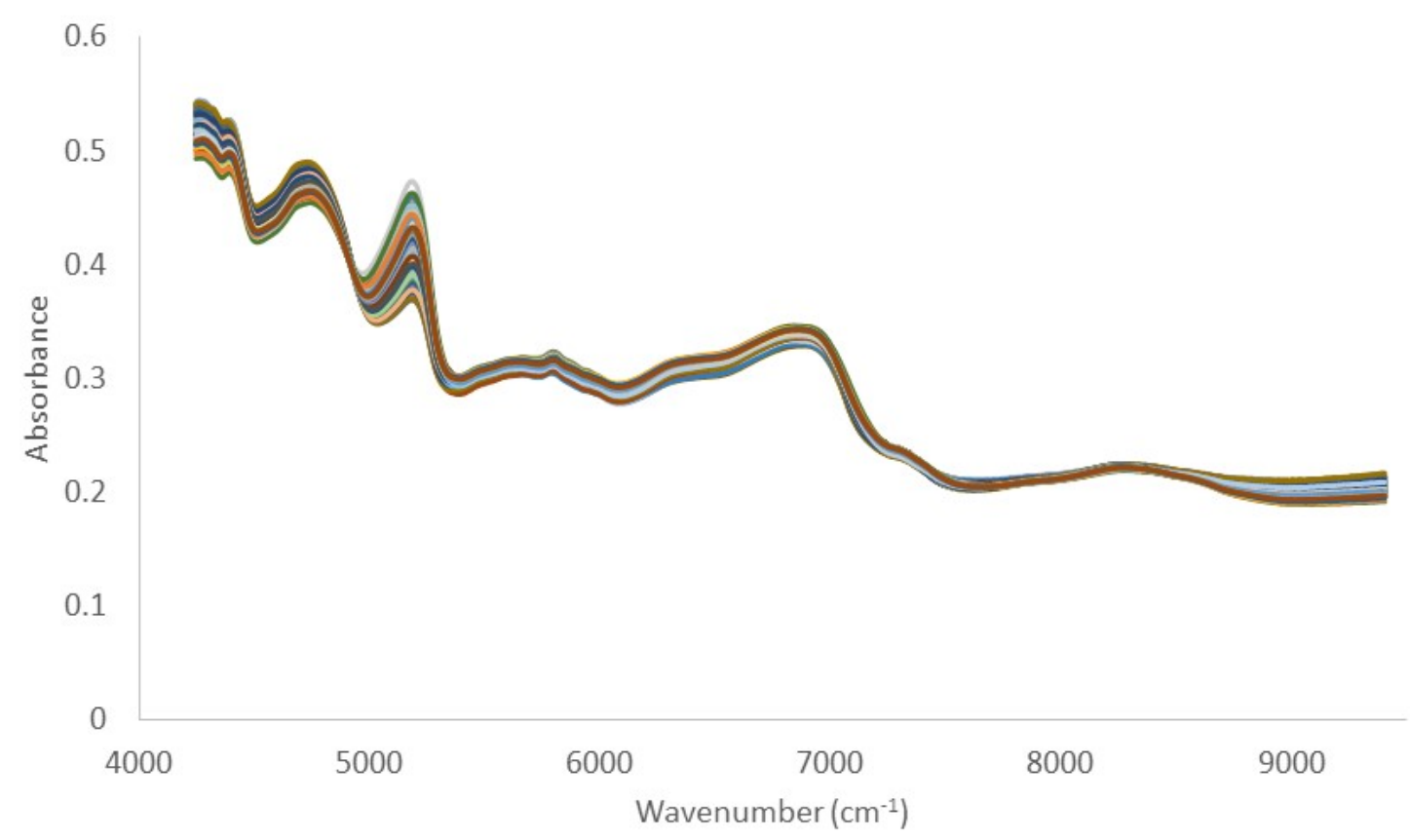

Figure 1. Absorbance (A) raw, and (B) multiplicative scatter correction spectra acquired for ground cane wood (Vitis vinifera) collected over four seasons (2010, 2011, 2012 and 2018). 


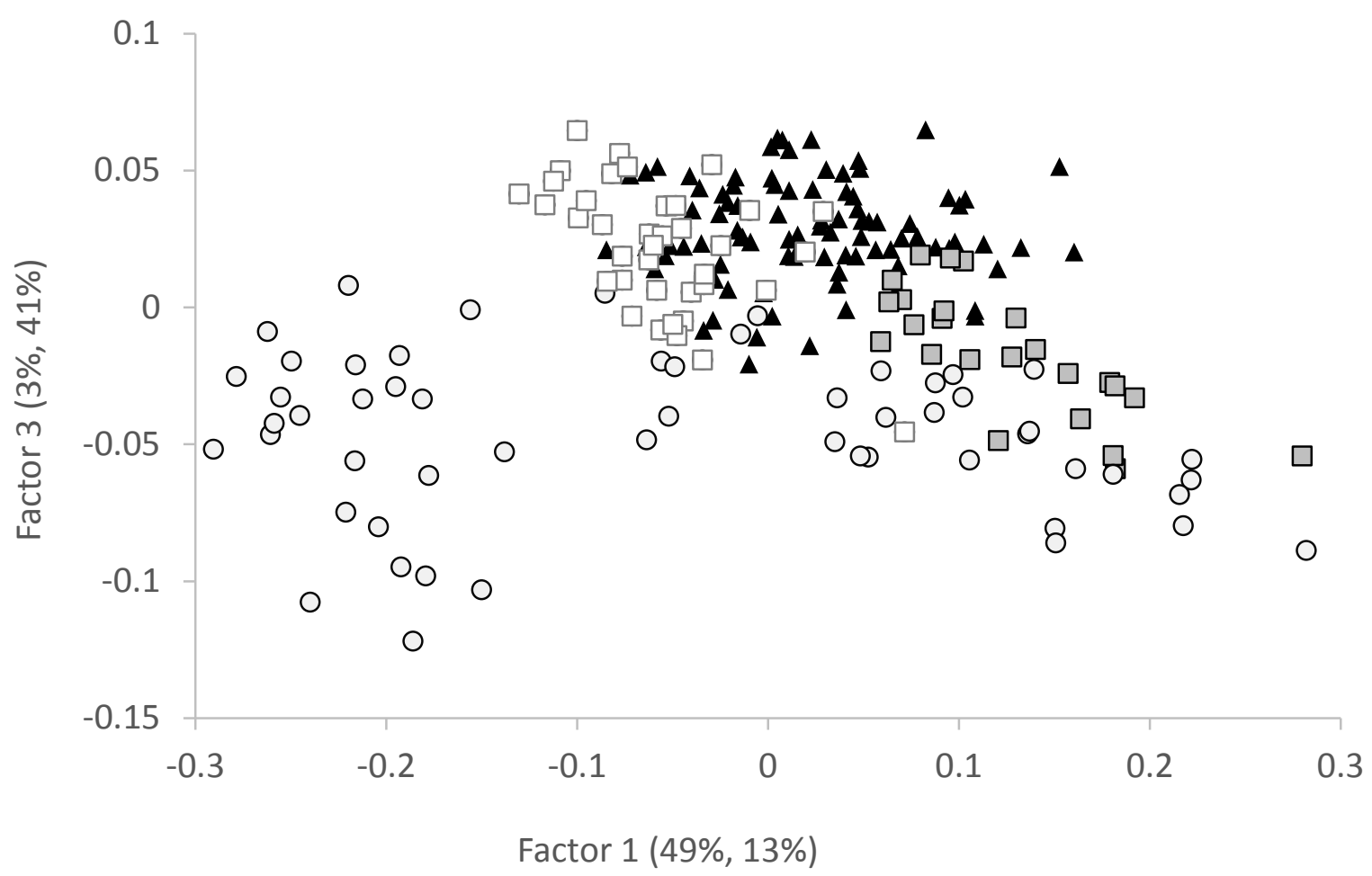

Figure 2. PLS score plot for starch concentration (\%) of ground cane wood (Vitis vinifera) obtained across four growing seasons [2010 (open square), 2011 (circle), 2012 (grey square) and 2018 (black triangle)]. 

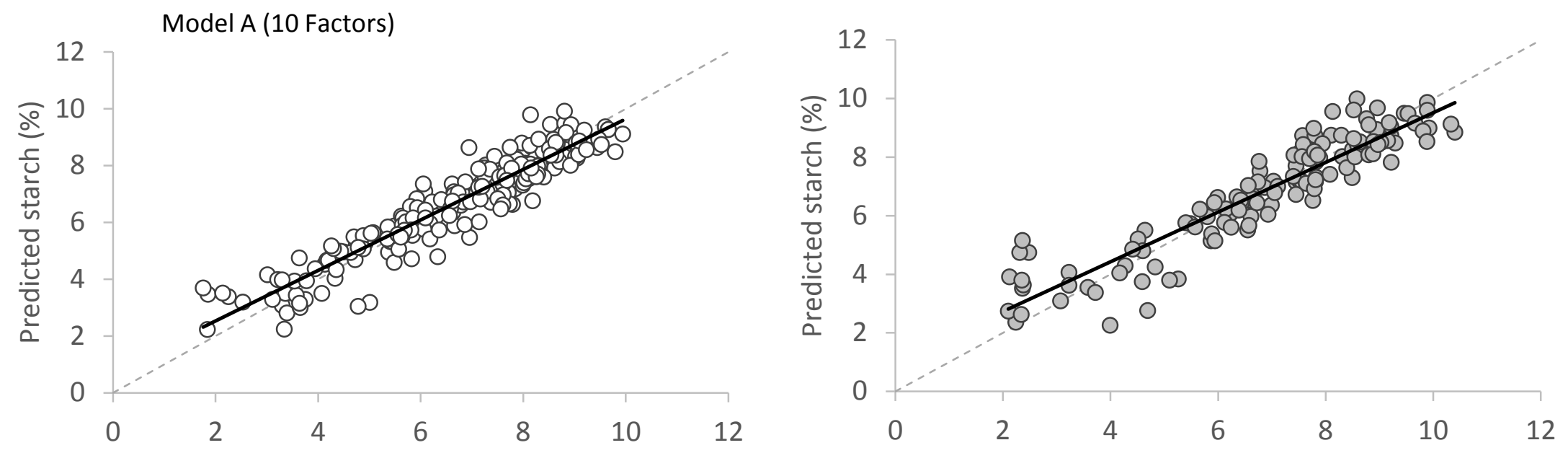

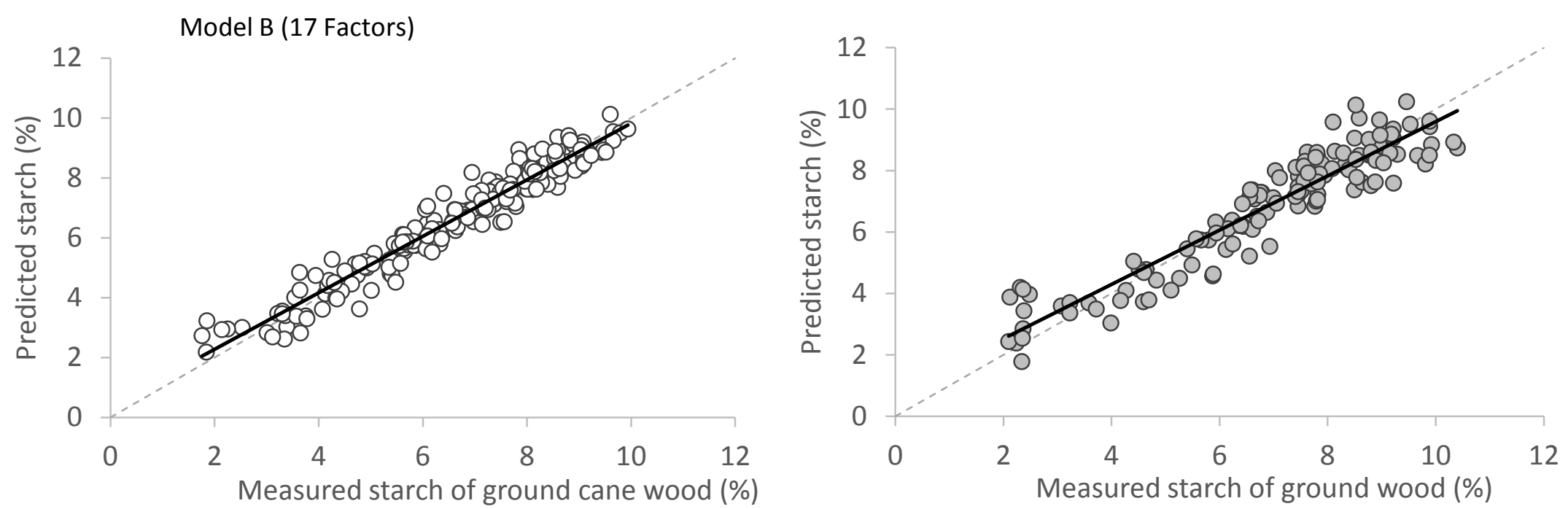
Figure 3. Relationship between starch concentration (\%) of ground cane wood (Vitis vinifera) measured with the standard reference methods (x-axis) and those predicted by NIR (y-axis) for data collected over four seasons (2010, 2011, 2012 and 2018) for Model A (10 Factors) and Model B (17 Factors). Linear fit in black while dotted line fit 1:1 line. $\mathrm{N}=$ 220 and 133 for predicted and independent validation models, respectively. 


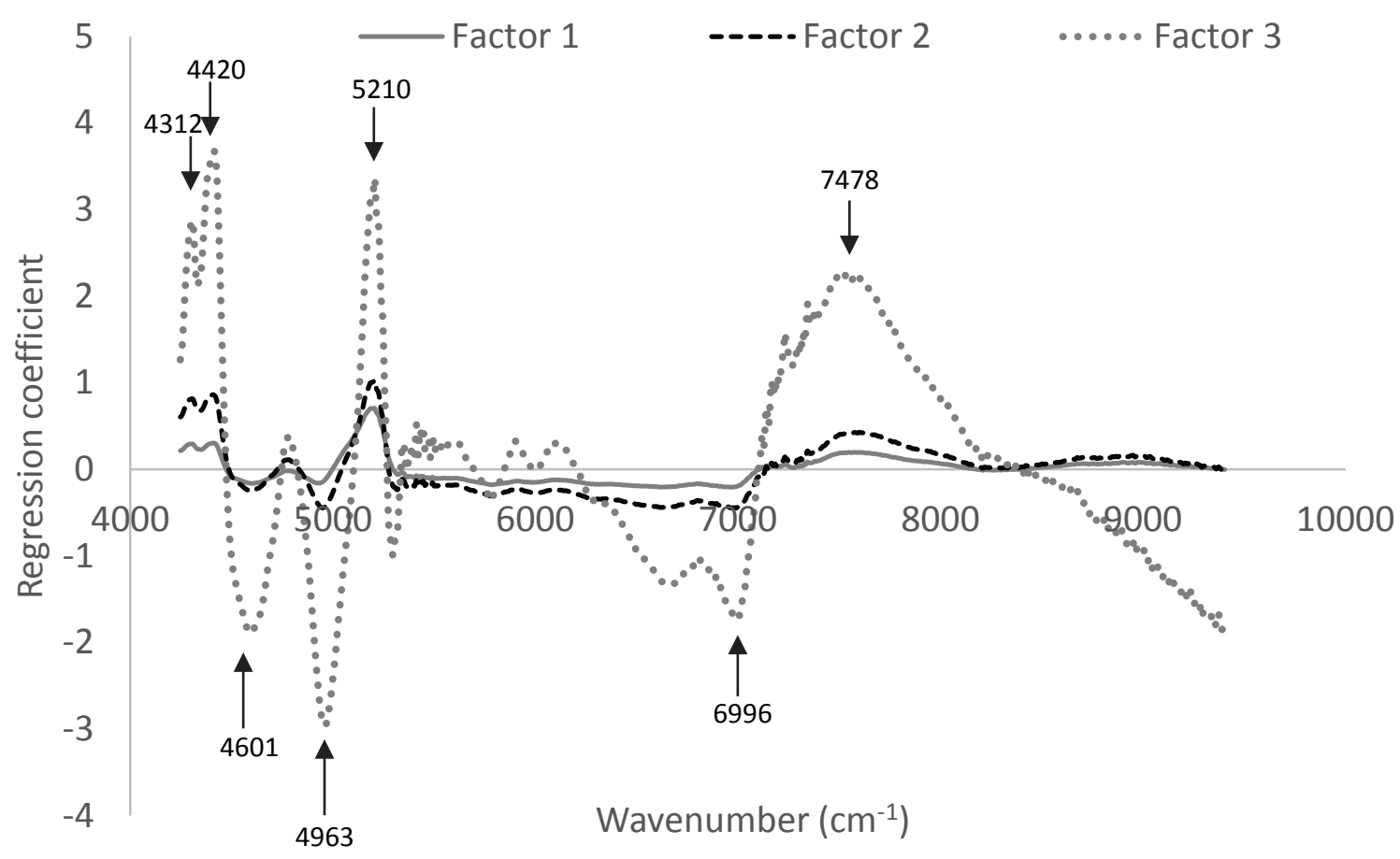

Figure 4. The first three partial least squares regression coefficients (Factors 1, 2 and 3) for the partial least square model developed to predict starch concentration (\%) using the transformed NIR spectrum collected on ground cane wood (Vitis vinifera) obtained across four growing seasons (2010, 2011, 2012 and 2018). 

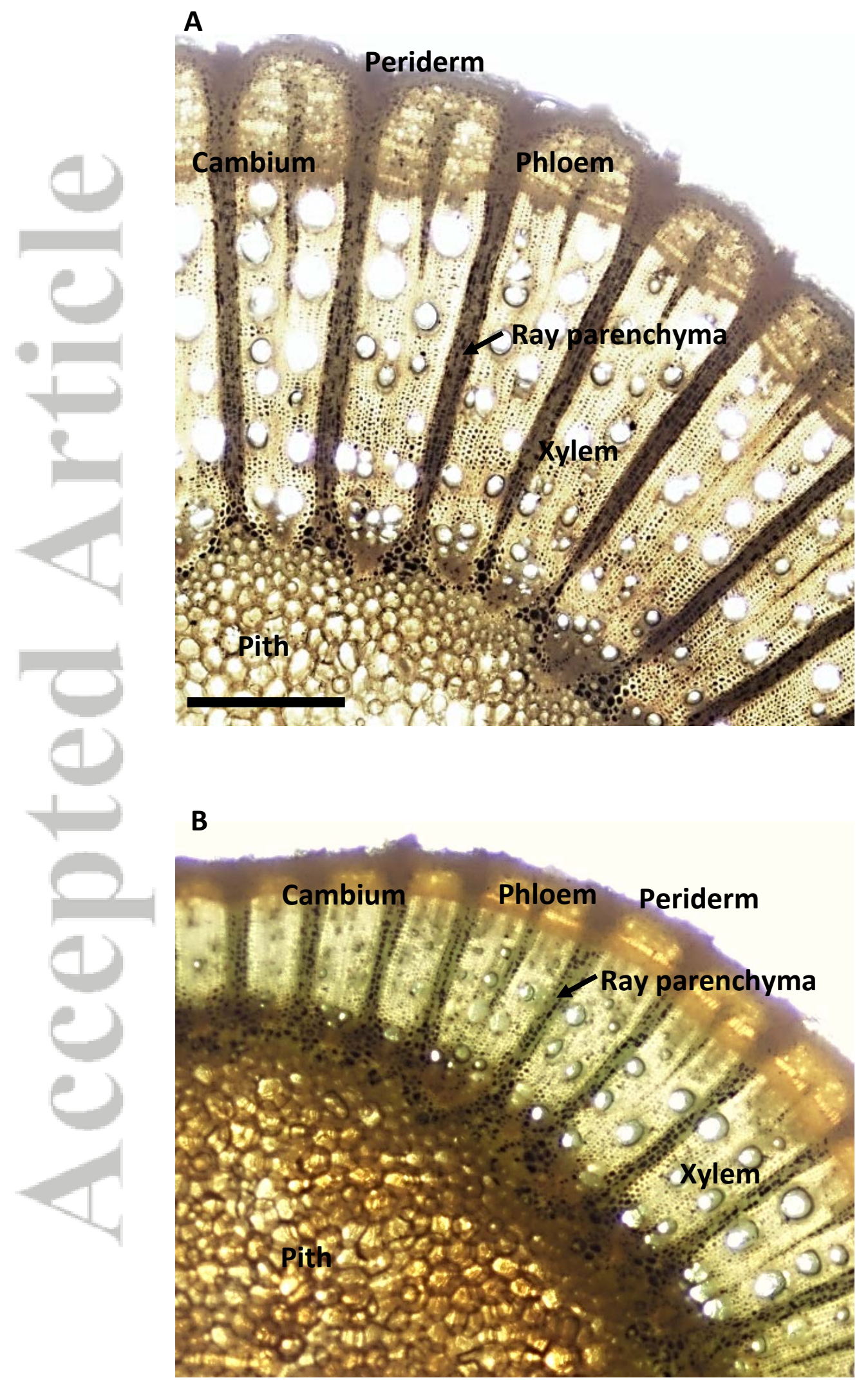

This article is protected by copyright. All rights reserved. 
Figure 5. Light micrographs of transverse section, stained with $1 \%$ aqueous solution of iodine-potassium iodide, showing starch grains (arrows) in the ray parenchyma of Chardonnay (A) and Pinot Noir cane wood (B). Scale bar $=2 \mathrm{~mm}$ 

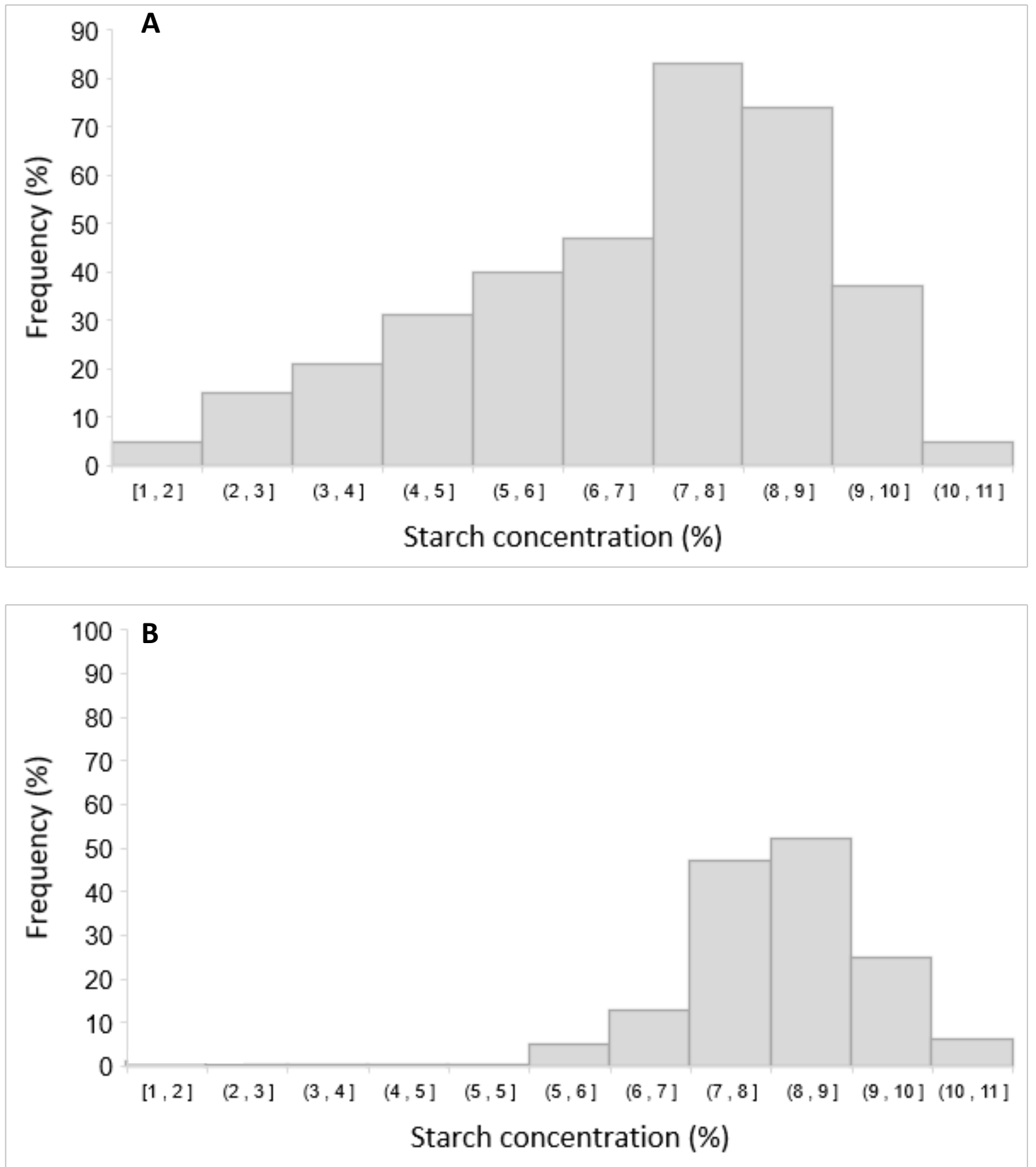

Appendix 1. Histograms of starch concentration (\%) of A) ground cane wood (Vitis vinifera) obtained across four growing seasons (2010, 2011, 2012 and 2018) and B) intact cane wood obtained in 2018.

This article is protected by copyright. All rights reserved. 